\title{
O COSMOPOLITISMO KANTIANO: UMA ANÁLISE DA FIGURA DO REFUGIADO À LUZ DO DIREITO À HOSPITALIDADE
}

\section{Gabriela dos Santos Paixão*}

Resumo: O objetivo é apresentar, do ponto de vista filosófico, a relação existente entre o cosmopolitismo kantiano e a figura do refugiado à luz do Direito à Hospitalidade. Orienta-se pelo procedimento da pesquisa bibliográfica. Apresenta o ideal filosófico de Kant para a instituição da Paz Perpétua com ênfase no Direito Cosmopolita. Demonstra a correspondência entre Direito Cosmopolita, Direitos Humanos e Direito Natural. Analisa o refugiado sob a perspectiva filosófica. Viabiliza o diálogo entre o cosmopolitismo e o refugiado. Por fim, conclui que há um entrelaçamento teórico e filosófico entre o refugiado e o Direito Cosmopolita baseando-se na concepção da cidadania universal.

Palavras-chave: Direito cosmopolita; Direito à hospitalidade; Refugiado; Cidadania universal; Filosofia do Direito.

\section{KANT'S COSMOPOLITANISM: AN ANALYSIS OF THE REFUGEE FIGURE IN THE LIGHT OF THE RIGHT TO HOSPITALITY}

\begin{abstract}
The objective is to present, from the philosophical point of view, the relation between Kant's cosmopolitanism and the refugee figure from the Right to Hospitality. It's guided by the bibliographic research procedure. It presents the philosophical ideal of Kant for the institution of Perpetual Peace with an emphasis on Cosmopolitan Law. It shows the correspondence between Cosmopolitan Law, Human Rights and Natural Law. Analyzes the refugee from a philosophical perspective. Enables dialogue between cosmopolitanism and refugee. Finally, it concludes that there is a theoretical and philosophical interweaving between the refugee and Cosmopolitan Law, based on the concept of universal citizenship.
\end{abstract}

Keywords: Cosmopolitan Law; Right to Hospitality; Refugee; Universal citizenship; Philosophy of Law

\section{INTRODUÇÃO}

Há mais de dois séculos o filósofo Immanuel Kant, preocupado com o status quo da época em que vivia, traçou as linhas do que pode ser considerado um direito público de toda a humanidade. Um projeto filosófico intitulado À Paz Perpétua, motivado pela instabilidade entre os Estados e pela preponderância da violência em detrimento das relações pacíficas. Kant vislumbrou no Direito um instrumento adequado para instituir a paz na Sociedade

\footnotetext{
* Mestranda no Programa de Pós-Graduação Stricto Sensu em Ciência Jurídica da Universidade Estadual do Norte do Paraná (PPGCJ/UENP) - Área de concentração: Teorias da Justiça: Justiça e Exclusão. Linha de Pesquisa: Estado e Responsabilidade: Questões Críticas. Graduação em Direito pela Faculdade de Direito da Alta Paulista (FADAP). E-mail: gabrielapaixao_@hotmail.com.
} 
Internacional, sustentando como uma das dimensões para o estabelecimento da paz o Direito Cosmopolita, fundamentado no Direito à Hospitalidade.

Assim, diante do atual cenário mundial, é possível e pertinente buscar resgatar o ideal filosófico de Kant, a fim de inseri-lo na realidade contemporânea como forma de instigar o interesse da sociedade por uma convivência pacífica e solidária. Afinal, no presente século, a política de guerra em oposição à cultura de paz tem configurado um panorama de graves e generalizadas violações de direitos humanos, desencadeando uma crise humanitária responsável por vitimar milhões de pessoas que sobrevivem em meio a conflitos armados, violência e perseguições; vítimas da instabilidade política e da própria decadência humana.

Nesse diapasão, a presente pesquisa tem como objetivo apresentar, como principal referencial teórico, o ideal do cosmopolitismo kantiano, a fim de relacioná-lo especificamente a uma das vítimas da atual crise humanitária: o refugiado. Assim, o escopo é apresentar, do ponto de vista filosófico, a relação existente entre o Direito Cosmopolita e a figura do refugiado, à luz do Direito à Hospitalidade Universal.

O presente estudo foi orientado pelo procedimento da pesquisa bibliográfica, e, para alcançar o seu objetivo, o trabalho foi desenvolvido da seguinte maneira: inicialmente apresenta-se o ideal filosófico de Kant para a instituição da Paz Perpétua, em que é denotada a ideia central do projeto de paz kantiano, com abordagem específica para o Direito Cosmopolita e sua fundamentação teórica.

Em seguida, faz-se a correspondência entre o Direito Cosmopolita, os Direitos Humanos e o Direito Natural, partindo da finalidade comum entre esses direitos: a preservação da dignidade humana. Na sequência apresenta-se a análise do refugiado sob uma perspectiva filosófica, como sendo o "Outro" que confronta o "Eu", oportunidade em que se coloca em discussão a necessidade de o refugiado ser aceito, protegido e acolhido em qualquer lugar do mundo, suplantando-se o medo, o preconceito, a discriminação e a xenofobia, para que prevaleça o sentimento hospitaleiro e a consciência de igualdade, solidariedade e respeito.

E, na última parte do estudo, viabiliza-se o diálogo entre o Direito Cosmopolita e a proteção do refugiado, com base no direito-dever à hospitalidade. Apresenta-se a visão de Kant, que reconhece a hospitalidade como direito; configurando-se como um conceito voltado à unidade e à proteção do ser humano, justificado pela necessidade da manutenção das relações pacíficas de que depende a própria sobrevivência humana. Assim, os homens devem se relacionar como iguais, como coproprietários de um mesmo espaço de coexistência. 
Por fim, como conclusão, afirma-se que há estreita relação entre o Direito Cosmopolita e a figura do refugiado. E que, diante da severa crise humanitária vivenciada, a humanidade necessita urgentemente compreender que existe uma interdependência humana, exigindo-se o afastamento de quaisquer tentativas de separação e antagonismo entre os povos. Assim, é fundamental apostar no ideal cosmopolita kantiano como uma nova forma de convivência em sociedade, em que se preze pela hospitalidade, pela solidariedade e pelo respeito mútuo, para que seja propagada e praticada a mensagem da cidadania universal.

\section{O IDEAL FILOSÓFICO DE KANT PARA A INSTITUIÇÃO DA PAZ PERPÉTUA}

Em 1795 o filósofo Immanuel Kant publicou o seu projeto filosófico intitulado À Paz Perpétua, um livro estruturado na forma de um documento jurídico fictício com o objetivo de apresentar meios para a instituição da paz entre as nações. É uma obra de Filosofia do Direito, que, segundo Guilherme Assis de Almeida, tem o propósito de oferecer "um arsenal teórico que estruture a comunidade internacional de um modo no qual a ação violenta não seja utilizada como forma de relacionamento entre as nações" (ALMEIDA, 2015, p. 13). Kant, portanto, propõe a paz como alternativa à violência, a fim de se substituir o estado de guerra, até então preponderante, pela convivência pacífica e harmônica entre os Estados.

Almeida (2015, p. 7) assinala que Kant não cria uma tecnologia apta a resolver os conflitos internacionais, mas elabora aos detentores de poder que não estão habituados à Filosofia e à sabedoria, "uma obra de reflexão filosófica sobre as relações internacionais de sua época, propondo uma superação desse status quo". De modo que À Paz Perpétua pode ser compreendida como uma meta a ser alcançada, cuja realização está condicionada à obediência e ao respeito às normas, aos valores e aos princípios contidos neste simbólico tratado de paz.

Na concepção kantiana o Direito é o agente de transformação capaz de converter o estado de guerra, predominante nas relações internacionais, em estado de paz. O Direito, portanto, na conjectura idealizada por Kant, opera como o instrumento adequado para se instituir o estado de paz na Sociedade Internacional. Para tanto, em seu tratado ficcional, o filósofo apresenta três dimensões relacionadas ao Direito que ele julga necessárias para fundar a paz: i) o Direito civil de Estado (direito interno) que deve assumir a forma republicana, e que diz respeito às relações dos Estados com os seus nacionais; ii) o Direito das Gentes (Direito Internacional) caracterizado pela federação de Estados livres e soberanos, mas unidos pela manutenção da paz; e iii) o Direito Cosmopolita (ius cosmopoliticum), responsável por 
regular as relações entre os homens e os Estados na convivência externa de influência recíproca.

São essas as três dimensões jurídicas indissociáveis e interdependentes propostas por Kant, contudo, a fim de se manter a fidelidade ao objetivo proposto neste trabalho, será feita, a partir de então, a análise específica de apenas uma delas: o Direito Cosmopolita.

\subsection{O Direito Cosmopolita}

Figurando como o Terceiro artigo definitivo para a Paz Perpétua, o Direito Cosmopolita pode ser compreendido como um direito público de toda a humanidade, fulcrado no direito-dever à hospitalidade. Nas palavras de Kant (2008, p. 11), a constituição jurídica à luz do Direito Cosmopolita "importa considerar os homens e os Estados, na sua relação externa de influência recíproca, como cidadãos de um estado universal da humanidade". A ideia do cosmopolitismo kantiano segue a lógica de que "se avançou tanto no estabelecimento de uma comunidade (mais ou menos estreita) entre os povos da Terra que a violação do direito num lugar da Terra se sente em todos os outros.” (KANT, 2008, p. 22).

Kant ambiciona, em seu tratado de paz, estabelecer relações pacíficas entre os Estados, reconhecendo e motivando a aproximação dos povos que, não obstante estejam localizados em partes afastadas do mundo, podem construir entre si relações cujo estreitamento é possível devido aos avanços da humanidade; possibilitando ao gênero humano aproximar-se de uma configuração cosmopolita. Afinal, na concepção de Kant, os homens devem suportar-se uns aos outros, isso porque "ninguém tem mais direito do que outro a estar num determinado lugar da Terra." (KANT, 2008, p. 20).

A ideia central desse projeto de estreitamento das relações entre pessoas que vivem em um território compartilhado, permite concluir, segundo Diego Carlos Zanella (2012), que a grande sugestão de Kant é a concepção de um Direito Cosmopolita fundamentado na compreensão de que cada ser humano é membro de uma comunidade mundial, não sendo admissível que um indivíduo, comportando-se de forma pacífica, seja por outro maltratado. Nesse sentido, é possível dizer que "o objetivo da teoria cosmopolita de Kant é o de assegurar uma condição que esteja em comum acordo com o direito de liberdade de todos os homens". (ZANELLA, 2012, p. 76).

Martin Wight classifica Kant dentre os revolucionários que acreditam apaixonadamente na unidade moral da Sociedade de Estados, acreditando, ainda, na 
transcendência dessa sociedade. "Para eles, a sociedade internacional como um todo transcende suas diversas partes; eles são cosmopolitas mais do que 'internacionalistas' e sua política e teoria internacional apresentam “um caráter missionário'.” (WIGHT, 1991, p. 8 apud ALMEIDA, 2015, p. 7-8).

Outros filósofos se debruçaram na corrente filosófica de Kant, a exemplo de Norberto Bobbio, Hannah Arendt e Jürgen Habermas. Na concepção de Habermas, em sua releitura e interpretação do modelo de paz oferecido por Kant, a paz deve ser vista como uma ação que permita materializar condições tangíveis de coexistência pacífica entre os povos da Terra, de modo que a paz não seja tão somente a inexistência de guerra. Isto é, para Habermas, a paz necessita ser concebida "como um processo que se desenvolve sem a intervenção da força, mas que não visa somente impedir o emprego da força, mas a realizar as condições reais de uma coexistência sem tensão entre os grupos e entre os povos." (HABERMAS, 1996, p. 71 apud ALMEIDA, 2015, p. 12).

Partindo da vertente que endossa a atuação pacífica dos Estados, Guilherme Assis de Almeida defende que o princípio normativo do mecanismo kantiano de instauração da paz perpétua é a não violência, ideia que se coaduna à filosofia habermasiana de instauração da paz. De tal modo, segundo Almeida (2015), a não violência não seria apenas um modo passivo de se resistir, mas uma forma de agir que supera a ação violenta por meio da criação de uma alternativa a ela, exercitando-se, portanto, uma forma de negar a violência. "A não violência é, também, uma resposta eficaz contra a violência, tendo em vista a preservação da integridade psicofísica do ser humano." (ALMEIDA, 2015, p. 5).

Resgatando a essência humanitária e igualitária que permeia a concepção do cosmopolitismo, Norberto Bobbio (2004, p. 54), ao interpretar o ideário de paz kantiano, reconhece o Direito Cosmopolita como sendo o direito do futuro, responsável por regular "não mais o direito entre Estados e súditos, não mais aquele entre os Estados particulares, mas o direito entre os cidadãos dos diversos Estados entre si”. Bobbio constrói um raciocínio voltado para a unidade e para a igualdade, sob influência das linhas inicialmente traçadas por Kant, agregando ao arcabouço jusfilosófico construído no entorno do cosmopolitismo a concepção de "cidadãos do mundo". Neste prisma, segundo Bobbio, "haverá paz estável, uma paz que não tenha a guerra como alternativa, somente quando existirem cidadãos não mais apenas deste ou daquele Estado, mas do mundo.” (BOBBIO, 2004, p. 6).

$\mathrm{Na}$ esteira da proposta de paz kantiana e do ius cosmopoliticum, Zygmunt Bauman (2013) também vislumbrou na conjectura contemporânea a necessidade da unidade entre os Estados com o fito de fomentar a integração humana, tarefa que julga demasiadamente 
urgente dada à interdependência dos povos que ocupam a superfície do planeta Terra; um vínculo incindível que pode resultar na vida compartilhada ou na morte conjunta. A ideia do autor se entrelaça com a conexão universal anunciada por Kant, sobre o estreitamento das relações neste mundo globalizado que faz com que a violência perpetrada em um lugar da Terra seja sentida em todos os outros. Este pensamento pode ser corroborado com a percepção de Bauman, pois, segundo ele,

\begin{abstract}
a modernidade necessita realizar outra tarefa, ainda mais formidável: elevar a integração humana até o nível da humanidade, incluindo toda a população do planeta. Por mais difícil e espinhosa que possa ser essa tarefa, ela é imperativa e urgente, pois, para um planeta caracterizado pela interdependência universal, tratase, literalmente, de uma questão de vida (compartilhada) ou morte (conjunta). (BAUMAN, 2013, p. 37).
\end{abstract}

O Direito Cosmopolita, portanto, à luz do ideal filosófico de Immanuel Kant para a instauração da Paz Perpétua, configura-se como um conceito voltado à unidade e à proteção do ser humano, principalmente por ser um direito fundamentado no direito-dever à hospitalidade. Ao analisar as relações humanas a nível internacional, Kant percebe que, em razão de toda a humanidade ser possuidora do direito de propriedade comum da superfície da Terra, não é admissível que os homens exerçam domínio sobre um território alheio ou que reajam hostilmente à presença de um estrangeiro. $\mathrm{O}$ ponto crucial que coroa o pensamento kantiano para a universalização de direitos é a importância por ele atribuída à hospitalidade universal, com isso, o filósofo abre espaço em sua construção teórica para a aproximação do Direito Cosmopolita a outros dois Direitos, quais sejam, os Direitos Humanos e o Direito Natural.

\title{
2.2 Direito Cosmopolita, Direitos Humanos e Direito Natural
}

A essência do ius cosmopoliticum é a defesa dos direitos inerentes ao homem na busca pelo estabelecimento da paz entre as nações, sendo este o canal que aproxima o cosmopolitismo kantiano aos Direitos Humanos e ao Direito Natural, visto que ambos são alimentados por objetivos comuns: a paz e a proteção do ser humano em sua dignidade e integridade. O ideial kantiano de expansão de direitos a todo ser humano na qualidade de integrantes de um mesmo cosmos, bem como as concepções de igualdade e de unidade compreendidas nas linhas de seu documento jurídico fictício, remetem à lógica universal norteadora dos direitos humanos. 
Costas Douzinas, em sua obra que combina a psicanálise e a Filosofia à historicidade dos direitos humanos, ressalta a importância de se escrever a história desses direitos fixando um ponto de partida no passado para que, a partir dele, sejam projetadas mudanças para o futuro. Segundo Douzinas (2009, p. 383), é do sofrimento do passado e das injustiças do presente que os direitos humanos extraem a sua força "e atuam como parasitas no corpo dos direitos, ao consumir o hospedeiro e projetar um futuro a partir de uma história jurídica um tanto insípida.”. Essa visão pode ser transportada à seara do Direito Cosmopolita, no sentido de que a humanidade olhe para o passado - e para o presente -, em um exercício reflexivo e racional e, diante da violência e das injustiças perpetradas, almeje adotar o ideal cosmopolita para o estabelecimento da paz.

O projeto de paz orquestrado por Kant, assim como os direitos humanos, também carrega uma finalidade missionária e utópica. Mas, “ao contrário das utopias clássicas, eles não extraem sua força de uma perfeição futura prevista e descrita, mas da dor e do desprezo sentidos por cidadãos dos Estados que proclamaram seu triunfo." (DOUZINAS, 2009, p. 383). O fim utópico dos direitos humanos é fundamental para a manutenção da sua finalidade. Do mesmo modo, a Paz Perpétua a ser instituída por meio da formação de uma unidade cosmopolita entre os habitantes da Terra, é uma concepção teórica e abstrata, mas que deve ser discutida e fomentada, a fim de que avanços nesse sentido possam surgir e a Sociedade Internacional consiga caminhar para uma constituição cosmopolita, nos moldes do que foi alvitrado por Kant.

Deve existir a utopia, a esperança no porvir, para que os direitos humanos não sejam arruinados. Deve existir a utopia para que ideais promissores de paz entre a humanidade se manifestem em meio a tanta violência. A humanidade não pode perder a esperança e a utopia. Entretanto, não é permitido que essa abstração venha completamente divorciada do que é sólido, pelo contrário, deve vir aparelhada de instrumentos concretos, de cunho normativo e institucional, capazes de possibilitar a consolidação do direito cosmopolita, a instauração da paz e, consequentemente, a afirmação dos direitos humanos.

Ainda sobre o fim utópico dos direitos humanos, Douzinas (2009, p. 384) ensina que o fim dos direitos humanos, bem como o fim do Direito Natural, "é a promessa do 'ainda não', da indeterminação da autocriação existencial diante do medo da incerteza e das certezas inautênticas do presente." Dessa forma, o filósofo conclui que quando os apologistas do pragmatismo anunciam o fim da ideologia, da história ou da utopia, "eles não assinalam o triunfo dos direitos humanos; ao contrário, eles colocam um fim nos direitos humanos. O fim 
dos direitos humanos chega quando eles perdem o seu fim utópico". (DOUZINAS, 2009, p. 384).

Seguindo a lógica da correlação entre o Direito Natural e os Direitos Humanos, Antônio Augusto Cançado Trindade, defende a constante identificação do "renascimento" do Direito Natural, o que ocorre de forma contínua, ainda que esse direito em nenhum momento tenha desaparecido, mas resistido, habitando dentre as diferentes épocas e sociedades. Segundo Cançado Trindade (2006) a renascença do Direito Natural tem sido uma reação ante o conservadorismo e a degeneração do positivismo jurídico. Remetendo à concepção de C.J. Friedrich, o autor registra: "Não mais se trata de um retorno ao direito natural clássico, mas sim da afirmação ou restauração de um padrão de justiça, pelo qual se avalia o direito positivo" (TRINDADE, 2006, p. 447).

Nesse mesmo diapasão, o renascimento do Direito Natural seria um meio de reforçar a universalidade dos direitos humanos, isso porque o Direito Natural pertence indistintamente a todos os seres humanos, diferentemente do direito positivado, que carece desse pertencimento universal,

O "renascimento" contínuo do direito natural reforça a universalidade dos direitos humanos, porquanto inerentes a todos os seres humanos, - em contraposição às normas positivas, que carecem de universalidade, por variarem de um meio social a outro. Daí se depreende a importância da personalidade jurídica do ser humano titular de direitos, inclusive como limite às manifestações arbitrárias do poder estatal. (TRINDADE, 2006, p. 447-448).

Douzinas (2009) também revela a contribuição significativa do Direito Natural na construção dos Direitos Humanos, sendo por ele tratados como "direitos companheiros", ainda que considerados dissociados historicamente. O autor pondera que o Direito Natural, progenitor dos direitos humanos, não está condenado a algo do passado que foi superado pelo direito positivo, mas que continua presente, permitindo que seja considerado na construção de um novo direito baseado na sua essência. Ele "habita as fronteiras da história, é um traço do passado e a prefiguração do futuro no presente" (DOUZINAS, 2009, p. 380), embora tenha tido frequentemente a sua atuação reduzida à visão imaginária, ficando suspenso entre mito e utopia, entre passado imemorável e futuro inatingível.

No mesmo sentido, é possível vislumbrar a essência do Direito Natural presente no cosmopolitismo kantiano a partir da declaração feita por Kant, de que o Direito Cosmopolita seria um complemento necessário de "código não escrito" ao direito político (direito interno) e ao direito das gentes (Direito Internacional); e como complemento da própria paz perpétua. 
Interpretando Kant, é razoável reconhecer a sua preocupação em oferecer um complemento às demais formas de direito estabelecidas para regular a convivência humana, enxergando neste complemento a condição para a aproximação da humanidade. Portanto, nas palavras de Kant, o Direito Cosmopolita

não é nenhuma representação fantástica e extravagante do direito, mas um complemento necessário de código não escrito, tanto do direito político como do direito das gentes, num direito público da humanidade em geral e, assim, um complemento da paz perpétua, em cuja contínua aproximação é possível encontrarse só sob esta condição. (KANT, 2008, p. 22).

Importante frisar que a presença do jusnaturalismo é significativa para a afirmação e consolidação dos direitos humanos, bem como para o reconhecimento do cumprimento de interesses humanos superiores, independentemente da existência de vínculo estabelecido por meio da nacionalidade, conforme declarado por Cançado Trindade (2006). Nessa seara de "eterno retorno" do Direito Natural, há o "reconhecimento de valores comuns superiores consubstanciados no imperativo de proteção do ser humano em quaisquer circunstâncias". (TRINDADE, 2006, p. 449).

A partir das reflexões aqui motivadas, fica evidente, portanto, a aproximação do Direito Cosmopolita aos Direitos Humanos e ao Direito Natural, considerando a finalidade utópica, a proteção da dignidade humana e o fundamento de uma convivência pacífica, justa e equânime entre os povos da Terra. A centralidade no ser humano é o ponto chave para a instauração de um ordenamento de paz que tenha como escopo promover valores universais que protejam o ser humano contra violações a direitos fundamentais. Assim, Eduardo Ramalho Rabenhorst, assevera:

não há dúvidas de que os direitos humanos, pelo menos desde a promulgação da Declaração de 1948, estão associados ao ideal kantiano de construção de um direito cosmopolita. Logo, o que poderia significar a globalização dos direitos humanos senão a universalização de normas jurídicas, sanções e procedimentos destinados a proteger e promover valores universais inquestionáveis? (RABENHORST, 2002, p. 23).

Rabenhorst associa o processo de internacionalização dos Direito Humanos, a que ele chama de "globalização dos direitos humanos", à construção do Direito Cosmopolita, o que faz sentido, pois o ideal preconizado por Kant pode ser visto parcialmente realizado na positivação dos direitos do homem. O fenômeno da positivação e da universalização dos direitos humanos, que eclodiu a partir do término da Segunda Grande Guerra, contou com o aparato normativo e institucional de uma organização composta por diferentes Estados, a Organização das Nações Unidas (ONU), que, por meio da Carta da ONU de 1945 e da 
Declaração Universal dos Direitos Humanos de 1948, deflagrou o processo de internacionalização e de institucionalização dos direitos humanos.

O histórico de violações de direitos humanos constatado ao final da Segunda Guerra Mundial propiciou, portanto, a transição e a alteração da figura jurídica do homem na ordem internacional; homem que passou a ser reconhecido como sujeito de direito destinatário da necessária proteção universal, a fim de que a humanidade, em suas próximas gerações, fosse preservada de sofrimentos semelhantes aos registrados à época. Isso representa um passo significativo no alcance da constituição cosmopolita, conquanto a concretização do ideal de paz esteja ainda distante. Mas a humanidade pode continuar avançando.

\section{O REFUGIADO SOB A PERSPECTIVA FILOSÓFICA: O “OUTRO” QUE CONFRONTA O "EU"}

A política de guerra em detrimento da cultura de paz tem traçado um panorama de graves e generalizadas violações de direitos humanos, desencadeando uma crise humanitária responsável pela produção de vítimas de conflitos armados, violência e perseguições; pessoas vitimadas pela instabilidade política e pela própria decadência humana. A tensão que reina sobre o território de determinados povos tem apresentado como saldo o deslocamento forçado de milhões de pessoas ao redor do mundo. E desse contingente de pessoas que forçosamente abandonam as suas origens em busca de proteção em terras mais seguras, desponta a figura do refugiado.

O refugiado, enquanto sujeito de direito na ordem internacional, adquiriu um status jurídico diverso do migrante voluntário, também chamado de migrante econômico, dada às singularidades de sua condição, tendo garantido uma proteção específica no âmbito da proteção da pessoa humana, configurada no Direito Internacional dos Refugiados (DIR). Há que se relacionar o Direito Internacional dos Refugiados ao Direito Internacional dos Direitos Humanos (DIDH), pois ambos são vertentes da proteção internacional da pessoa humana, ao lado do Direito Humanitário, trazendo como marco protetivo a violação dos direitos humanos, cuja matriz axiológica comum é a própria Declaração de 1948. A relação de similaridade e complementaridade permite considerar o DIR como um dos eixos do DIDH lato sensu, voltado às especificidades da questão do refugiado. Agni Castro Pita, defende essa relação:

O Direito Internacional dos Refugiados não pode ser concebido fora do marco do Direito Internacional dos Direitos Humanos. É na violação dos direitos humanos que se radica a causa fundamental pela qual as pessoas se veem coagidas a abandonar seu país de origem e solicitar asilo. O respeito e vigência dos direitos humanos nos 
países de origem é a melhor maneira de prevenir os deslocamentos forçados de pessoas. No mesmo sentido, o respeito aos direitos humanos é crucial para garantir a admissão e a proteção eficaz dos refugiados nos países de asilo. (PITA, 2016, p. 7).

Existe uma definição objetiva para que o indivíduo possa ser reconhecido como refugiado e passe a gozar da proteção de um Estado na seara do Direito Internacional dos Refugiados. Grosso modo, à luz da Convenção de Genebra de 1951 Relativa ao Estatuto dos Refugiados, e da definição ampliada de refugiado adotada em contextos regionais, refugiado é o indivíduo que se encontra fora do país de sua nacionalidade ou de residência habitual devido a bem fundado temor de perseguição por motivos de raça, religião, nacionalidade, pertencimento a determinado grupo social ou opiniões políticas, bem como toda pessoa que tiver de deixar o seu país de origem ou de residência devido a grave e generalizada violação de direitos humanos.

Destarte, superada a definição de refugiado na ótica jurídica, esta que teve serventia no presente estudo apenas a título de contextualização e localização do refugiado no panorama da crise humanitária, resta iniciar a abordagem da figura do refugiado em uma perspectiva filosófica, pois, consoante ensina Pita (2016), reproduzindo a constatação de António Guterres ${ }^{1}$, há algo mais profundo por trás da problemática dos refugiados, o que requer uma análise voltada à dificuldade existente em se aceitar a circulação de pessoas pelo mundo da mesma forma com que bens e capitais têm a sua circulação permitida sem óbices.

\begin{abstract}
A problemática dos refugiados requer uma análise adaptada a um mundo em constante mudança. Deve ser analisada no contexto de um mundo globalizado, o qual, como já o manifestou o então Alto Comissário António Guterres, tem duas fases: por um lado, os bens e o capital circulam pelo mundo todo com grande facilidade, por outro, a circulação de pessoas se torna cada vez mais restritiva, em particular, a dos segmentos mais vulneráveis, incluindo os refugiados e solicitantes de asilo. (PITA, 2016, p. 5).
\end{abstract}

Essa afirmação faz erigir a reflexão sobre qual é o nível de abertura das diversas sociedades do mundo para o acolhimento das pessoas refugiadas que reclamam de seus conterrâneos um mínimo de amparo e de proteção. O refugiado é o símbolo da vulnerabilidade humana, o homem que se vê despido de sua própria terra, de sua família e da sua história de uma forma repentina e involuntária, motivado pela necessidade de sobrevivência. O refugiado viaja na companhia inevitável do medo e da incerteza, sentimentos latentes que o castigam sobremaneira desde o momento da partida até a chegada às fronteiras dos países desconhecidos. Portanto, as palavras de Flávia Piovesan corroboram e

${ }^{1}$ Exerceu mandato de Alto Comissário no Alto Comissariado das Nações Unidas para os Refugiados (ACNUR) de 2005 a 2015, sendo sucedido pelo atual Alto Comissário, Filippo Grandi. 
sintetizam o raciocínio: "Os refugiados abandonam tudo em troca de um futuro incerto e uma terra desconhecida." (PIOVESAN, 2016, p. 178 apud GILBERTO, 2016, p. 33).

Costas Douzinas, aponta para a necessidade do reconhecimento da "humanidade" do refugiado, pois, segundo ele, há uma "objetificação" do refugiado. Isto é, no julgamento de casos concretos em que se analisa o reconhecimento ou não do status de refugiado, o indivíduo é reduzido a um objeto de "conhecimento totalmente transparente ou em uma entidade quase-humana desprovida das necessidades mínimas de sobrevivência e abandonado aos desígnios da benevolência pública ou da caridade privada.” (DOUZINAS, 2009, p. 367). Douzinas (2009, p. 63) acrescenta ainda que a figura do refugiado "coloca em xeque as reivindicações de universalização dos direitos humanos”. Ademais, na visão do autor,

\begin{abstract}
os refugiados não são tratados como sujeitos, mas como o contrário ou oposto do sujeito, ou como não-sujeitos ou objetos. Se eles são objetos, não são seres humanos, portanto, não fazem jus nem mesmo às necessidades mínimais de vida, como alimento, abrigo, roupas, um refúgio. Se eles são não-sujeitos, não têm direitos nem prerrogativas; a lei nada deve a eles, e sua sobrevivência fica a cargo da benevolência do Estado ou da filantropia privada. (DOUZINAS, 2009, p. 367).
\end{abstract}

Zygmunt Bauman (2017) adiciona à temática do refugiado a questão da moral. Segundo ele, vive-se, nas sociedades hodiernas, a redução do domínio das obrigações morais que o ser humano estaria pronto para admitir e assumir como uma responsabilidade diária, cotidiana, e "não apenas durante as festivas explosões de curta duração de solidariedade e preocupação desencadeadas pelas imagens midiáticas de sucessivas tragédias espetaculares na interminável saga dos migrantes" (BAUMAN, 2017, p. 79). Isso é algo que acontece hoje de forma acentuada opondo-se ao espaço da interdependência humana, intercalando entre os festivais morais, espaços de manifestação da clara distinção feita entre as pessoas, dividindo o mundo entre "nós" e "eles",

\footnotetext{
O problema é que, durante os prolongados espaços de tempo que separam esses festivais morais, tendemos a viver num mundo claramente separado, em aparência de modo irreversível, entre "nós" e "eles". Essa fissura não exige uma "negação moral de si". Pelo contrário, cotidianamente, e em escala maciça, essa brecha gera esforços frenéticos para colocar impulsos morais - jamais mortos, porém adormecidos na maior parte do tempo - a serviço da divisão e do antagonismo sociais e políticos. (BAUMAN, 2017, p. 79).
}

A figura do refugiado estabelece, portanto, um confronto entre o "nós" e o "eles", entre o "eu" e o "outro". Essa divisão é resultado de uma errônea concepção do Outro como sendo alguém ameaçador. "Um rosto com medo ou dor vem, em sua singularidade, para assombrar seus semelhantes tanto quanto seus perseguidores". (DOUZINAS, 2009, p. 370). A 
imagem de um ser humano desprovido de tudo quanto possuía e que inicia uma nova jornada a partir do vazio que é preenchido apenas com a esperança é o símbolo da fragilidade, da insegurança e da instabilidade humana. Como assevera Douzinas (2009, p. 363), o refugiado “é representante da total alteridade e o símbolo do nosso próprio exílio, o sinal de que o ego não consegue encontrar paz e segurança em uma existência isolada e protegida”. Assim,

não há lembrança maior das demandas da ética que o pedido de asilo por uma pessoa perseguida, nem encarnação empírica mais forte do Outro que o verdadeiro refugiado. Esta é a razão pela qual o refugiado é visto como tal ameaça. Sua chegada nos lembra de que nós também, em nossas moradias seguras, jamais estamos em casa [...] (DOUZINAS, 2009, p. 363).

Ao considerar os problemas gerados pela crise migratória atual, Bauman (2017, p. 104) adverte que tais problemas pertencem a uma complexa e controversa categoria; problemas que têm sido intensificados pelo pânico provocado pelo tema. O dilema surge na medida em que o imperativo categórico da moral entra em conflito direto com o medo do grande desconhecido "simbolizado pelas massas de estranhos à nossa porta". Ou seja, "O medo impulsivo gerado pela visão de migrantes portando inescrutáveis perigos entra em luta com o impulso moral estimulado pela visão da miséria humana”. (BAUMAN, 2017, p. 104).

O medo do Outro (do refugiado) revela a dificuldade e o receio que o homem possui de aceitá-lo como seu semelhante, pois, se assim o fizer, reconhecerá a sua própria vulnerabilidade, e é mais cômodo ao homem conservar a sua vida sem qualquer interferência "estranha", renunciando ao imperativo moral para salvaguardar a sua segurança frente àqueles que são rotulados como uma ameaça; aqueles cuja fragilidade ora impulsiona a compaixão e a solidariedade de seus semelhantes ora motiva o preconceito, a discriminação, a xenofobia e a hostilidade. Na visão de Bauman (2013), o refugiado sem teto, o que está desarraigado, e que representa o círculo dos "que não fazem parte", dos que buscam, porém, não encontram asilo, "tendem a atrair nosso ressentimento e aversão. Todas essas pessoas parecem ter sido feitas sob medida para os nossos medos." (BAUMAN, 2013, p. 199).

Segundo Douzinas (2009, p. 368), o refugiado “desafia a retidão e a propriedade do Eu, ele nega a casa, o convívio familiar e o território nacional ao ficar desprotegido e sem âncora. Ele fica vagando, é nômade, delirante e ameaçador.”. Assim, a sua condição de ser humano desprovido de proteção simboliza a negação da afinidade entre os homens, assumindo o estigma de ser o Outro ameaçador, quando, na verdade, é alguém que não levanta qualquer bandeira que represente o perigo, mas que ostenta, na bandeira que segue 
hasteada em seu barco que cruza fronteiras e territórios, o símbolo da alteridade e da luta por dignidade.

Há, por vezes, a relutância em incluir o refugiado no círculo que compreende o "nós", logicamente porque essa inclusão é capaz de inseri-lo em um contexto de semelhança. E como restou corroborado: "Confrontar o refugiado levanta a possibilidade de que nós, igualmente, somos refugiados, o que implica meu dever não apenas de aceitar o Outro, mas também de aceitar que sou um Outro" (DOUZINAS, 2009, p. 370). É nesse sentido que se faz necessário facilitar o diálogo entre o Direito Cosmopolita e o refugiado, possibilitando demonstrar que, por ser a humanidade pertencente a um só cosmos, ocupante da mesma superfície da Terra, o refugiado desponta como sujeito de direito carecedor de proteção, de respeito e da aceitação amistosa por parte das sociedades do mundo.

O refugiado precisa ser tratado como semelhante e como parte integrante do todo, não como parte de uma população remanescente. Afinal, é na figura do refugiado que se opera a exteriorização do Eu.

O refugiado está dentro de nós. Ao lutar com o refugiado, lutamos com nosso inconsciente esse lugar impróprio em meio de nós próprios [...] Ao mandá-lo embora, pensamos negar o trauma, pensamos que protegemos a nós mesmos do terrível reconhecimento de que o Outro, o refugiado está em nós, e que não podemos evitar viver como Outros. (DOUZINAS, 2009, p. 371).

Assim, é coerente o argumento de que o ius cosmopoliticum inspira a ideia do pertencimento mundial na garantida da dignidade da pessoa independentemente de sua origem ou condição, justificando a necessidade de o refugiado ser aceito, protegido e acolhido em qualquer lugar do mundo pelo simples fato de ser: humano. Portanto, o refugiado não é o Outro, não é o estranho; ele é, na acepção de Bobbio, cidadão do mundo, e conterrâneo de cada indivíduo que habita o idealizado Estado Universal.

\section{DIÁLOGO ENTRE O COSMOPOLITISMO KANTIANO E A FIGURA DO REFUGIADO: O DIREITO-DEVER À HOSPITALIDADE}

Consoante destacado ao longo deste trabalho há uma relação expressiva entre o ideal filosófico kantiano e os direitos humanos, na medida em que o Direito Cosmopolita está centrado na unidade e na igualdade entre todos os ocupantes da Terra, que, justamente por partilharem de uma mesma superfície não possuem autoridade para subjugarem uns aos outros. Kant vislumbra a unidade olhando para o planeta Terra e não para a separação provocada pela delimitação territorial de um Estado. Ele também não despreza a existência de 
diferentes nações e a consequente soberania que cada uma delas possui, mas, pugna pela harmonização e pela coexistência motivada por um objetivo comum: a manutenção da paz. Assim, o que Kant reivindica

não é o cancelamento da distinção entre terras (países, Estados soberanos e autônomos, vistos e tratados por suas respectivas populações como suas pátrias de direito), mas "um direito de se associar" (comunicar, entrar numa interação amigável e por fim tentar estabelecer laços de amizade mutuamente benéficos, que se presuma serem enriquecedores do ponto de vista espiritual). $\mathrm{O}$ que Kant reivindica é a substituição da hostilidade pela hospitalidade. (BAUMAN, 2017, p. 74).

Partindo dessa reivindicação de Kant pela substituição da hostilidade pela hospitalidade, é possível estabelecer a aproximação entre a teoria cosmopolita e a figura do refugiado, relação que se dá em razão do princípio motriz que fundamenta e direciona o Direito Cosmopolita: o princípio da hospitalidade universal. Tal princípio preconiza o respeito ao ser humano independentemente de seu país de origem ou do lugar em que se encontre, dando ensejo à ideia de uma cidadania universal que garanta a proteção da pessoa na efetivação dos direitos humanos, ratificando a essência desses direitos que não devem estar condicionados ao direito interno de cada Estado soberano, mas que necessitam ser efetivados em âmbito universal. As palavras de Kant corroboram, ainda, que a "hospitalidade significa aqui o direito de um estrangeiro a não ser tratado com hostilidade em virtude da sua vinda ao território de outro." (KANT, 2008, p. 20).

O ius cosmopoliticum limita-se, então, ao Direito à Hospitalidade, que compreende o direito de todo estrangeiro não ser tratado de modo hostil quando estiver em território diverso de sua nacionalidade, e o "dever de todo Estado não usurpar da hospitalidade que lhe é oferecida pela população de um determinado Estado ou território e transformar o seu direito de visita num violento ato de conquista" (ALMEIDA, 2015, p. 11-12). Existindo hoje um avanço, desde a concepção kantiana, revelado no princípio da não devolução (ou non refoulement) que acentua a proteção ao refugiado, pois, além de ser vedado o tratamento hostil àqueles que adentram em território alheio, é ainda proibido o rechaço. Tal princípio é considerado "a pedra angular da proteção internacional de refugiados, princípio estreitamente vinculado ao de gozar de uma série de direitos civis, políticos, econômicos, sociais e culturais." (PITA, 2016, p. 7-8).

Neste prisma, partindo do princípio da hospitalidade mútua "Kant divisou a possibilidade e a perspectiva da paz universal, pondo fim à longa história de guerras fratricidas que castigaram o continente europeu" (BAUMAN, 2017, p. 74). Na concepção cosmopolita há o encorajamento a uma missão altruísta diante da crise humanitária que tem 
motivado a situação de refúgio. No entanto, não é apenas de altruísmo que se constrói a mensagem do cosmopolitismo, pois a hospitalidade que fundamenta essa teoria é tida como um direito-dever. Quando Kant expõe a sua ideia ele pondera, incisivamente, que a base do cosmopolitismo - o Direito à Hospitalidade - não se trata de mera filantropia, mas sim de direito. Logo, adverte: "Fala-se aqui, como nos artigos anteriores, não de filantropia, mas de direito.” (KANT, 2008, p. 20).

De modo semelhante, Gabriel Gualano de Godoy, defende a hospitalidade como direito, remetendo o seu pensamento à matriz ideológica do cosmopolitismo em Kant. Segundo Godoy, o campo do Direito precisará ser mobilizado se a ocorrência de refugiados persistir, para que sejam reequilibradas as instabilidades a partir de ações humanitárias e apolíticas.

Se a política contemporânea não se coloca a tarefa de cessar de produzir refugiados, será preciso que o campo do Direito seja mobilizado. Numa sociedade em que o medo é o afeto central, será o Direito que pretenderá reequilibrar as instabilidades com uma resposta humanitária, apolítica. Nesses termos é que a hospitalidade passa a ser direito, e se o conceito de refugiado e a obrigação de não devolução são normas de jus cogens, tudo se passa como se estivéssemos na era kantiana do direito à hospitalidade universal, a era da cosmopolítica da hospitalidade. (GODOY, 2016, p. 64).

Segundo Almeida (2015, p. 80), Kant enxerga na figura do refugiado "o resultado de uma ação jurídica no âmbito do Direito Cosmopolita”. Esse pensamento sedimenta a relação que se objetiva estabelecer, pois, quando o ius cosmopoliticum propaga a ideia de se instituir condições mútuas, pacíficas e harmônicas de convivência, apartando qualquer tipo de divisão e antagonismo entre os povos, esse projeto converge com a necessidade de proteção à pessoa em situação de refúgio. E quando ações nesse sentido são promovidas, o direito à hospitalidade começa a se materializar, caminhando para o estabelecimento de uma comunidade integrante e coesa, de modo a possibilitar a inclusão do "eles" na concepção de "nós", até a chegada de uma constituição semelhante à idealizada por Kant.

Sobre o Direito Cosmopolita, Bauman pactua com a ideia do estreitamente das relações entre os povos e sugere a criação de um equivalente global, divergindo da matriz ideológica principiada por Kant, porém, adequando-a à contemporaneidade, partindo do pressuposto de que a condução para um planeta social não depende de Estados territorialmente soberanos, e sim de "organizações e associações não governamentais cosmopolitas, aquelas que atingem diretamente as pessoas necessitadas por sobre as cabeças dos governos locais ‘soberanos' e sem interferência deles”. (BAUMAN, 2013, p. 38). 
Contudo, vislumbra-se que a hospitalidade deve ser garantida como um direito cujo núcleo essencial é a própria dignidade humana, pois diante do cenário configurado pela violação de direitos, o mínimo que pode ser concedido às vítimas dessa crise humanitária é uma acolhida digna. Bauman apresentou o seguinte panorama:

Crianças afogadas, muros apressadamente erguidos, cercas de arame farpado, campos de concentração superlotados e competindo entre si para acrescentar o insulto de tratarem os migrantes como batatas quentes às injúrias do exílio, de escapar por pouco dos perigos enervantes da viagem rumo à segurança. (BAUMAN, 2017, p. 8).

Todas as situações supracitadas não refletem a hospitalidade, pelo contrário, revelam a preocupante situação da decadência humana. Isso porque o ser humano vem sendo cada vez mais reduzido à qualidade de coisa, o que chega a ser contraditório, mesmo porque as coisas e as mercadorias ainda estão sendo bem mais receptíveis e bem-vindas em outros territórios do que o próprio homem. Permitindo-se concluir que o alcance do Direito Cosmopolita está atrelado a um progresso moral; progresso que a humanidade necessita buscar guiando-se pela capacidade ética que o ser humano possui para contribuir positivamente na vida do seu semelhante. Tarefa que demanda prática contínua, um exercício cotidiano em busca de um status superior no cuidado com a causa humanitária. E essa dinâmica deve ser provocada, motivada e construída paulatinamente, pois, "a conduta moral não é algo que ocorra naturalmente". (ARENDT, 2003, p. 62 apud BAUMAN, 2017, p. 97).

Assim, o Direito à Hospitalidade, como base norteadora do Direito Cosmopolita, é uma das raízes sobre a qual está fulcrado o projeto filosófico da Paz Perpétua traçado por Kant. E a relação existente entre a figura do refugiado e o Direito Cosmopolita está no fato de a acolhida e a proteção ao refugiado constituírem uma ação que se concretiza no âmbito jurídico e que reflete a sua essência humanitária no estabelecimento de relações recíprocas que possibilitam à humanidade caminhar para a instauração da paz.

O Direito Cosmopolita, portanto, prega a necessidade de os homens se relacionarem como iguais, como coproprietários de um mesmo espaço de coexistência, mensagem que se intensifica quando se está diante da figura do refugiado, devido à condição específica que ele ostenta nesse cenário de violações a direitos humanos, tendo em vista que "o homem pode perder todos os chamados Direitos do Homem sem perder sua qualidade essencial de homem, sua dignidade humana. Só a perda da própria comunidade é que o expulsa da humanidade" (ARENDT, 1989, p. 331 apud ALMEIDA, 2018, p. 142). Destarte, à luz do cosmopolitismo, é direito do refugiado buscar proteção em outros territórios, e é dever dos Estados sustentarem 
as mínimas condições de hospitalidade, trazendo o homem, que perdeu a sua comunidade, de volta ao seio da humanidade.

\section{CONCLUSÃO}

O trabalho teve como proposta e objetivo geral estabelecer e demonstrar a relação existente entre a figura do refugiado e o Direito Cosmopolita, a partir da análise bibliográfica. Assim, ao tomar como ponto de partida o estudo do ideário da Paz Perpétua projetado por Kant foi possível evidenciar no ius cosmopoliticum - uma das dimensões jurídicas necessárias à instituição da paz entre os povos - o entrelaçamento teórico e filosófico entre o refugiado e a base norteadora do cosmopolitismo kantiano: o Direito à Hospitalidade Universal.

Kant, quando orquestrou a ideia do cosmopolitismo, enxergou a necessidade de uma interação real - normativa e prática - entre os Estados, a fim de se garantir a dignidade do ser humano em qualquer lugar da Terra. A concepção de cidadão do mundo é a ideia motriz que fundamenta a ação protetiva no acolhimento de pessoas que percorrem as fronteiras dos Estados em busca de refúgio. Portanto, fica sedimentada a noção de que o Direito à Hospitalidade enseja a concessão do status de cidadão universal a todos os seres humanos, sendo possível compreender que embora existam as limitações institucionais e as políticas internas de cada Estado, o que se preza na conotação de cidadania universal é a ideia da proteção do indivíduo enquanto ser humano, motivando o seu acolhimento amistoso por parte dos países anfitriões, tendo sempre em mira a preservação de sua dignidade enquanto pessoa.

Ao ser estabelecida a aproximação entre o Direito Cosmopolita, os Direitos Humanos e o Direito Natural, as reflexões permitiram corroborar a correspondência entre eles considerando o escopo comum da proteção da dignidade humana. A centralidade no ser humano é tida como o ponto chave, a matriz ideológica que serve de parâmetro a esses direitos na busca pela instauração de um ordenamento de paz que tenha como meta promover valores universais que protejam o ser humano contra violações a direitos fundamentais.

A partir da análise do refugiado sob a ótica filosófica foi possível identificar a acentuada marginalização do homem, constatando-se que existe algo mais profundo por trás da problemática dos refugiados devido à dificuldade em se aceitar a circulação de pessoas com a mesma facilidade com que os bens e os capitais circulam pelo mundo. O medo do Outro revelou a relutância do homem em aceitá-lo como seu semelhante, pois isso envolveria o reconhecimento de sua própria vulnerabilidade. Chegando-se à conclusão de que "não há 
qualquer garantia de que o afeto suplantará o medo. Entretanto, a experiência nos ensina que, quando o medo do Outro, do estrangeiro, do judeu, do refugiado, torna-se sua lógica institucional, os direitos humanos perdem seu valor protetor contra o Estado." (DOUZINAS, 2009, p. 380).

$\mathrm{Na}$ abordagem do ius cosmopoliticum, restou provado que acolher o refugiado em sinal de hospitalidade não é ato de mera filantropia, mas transcende de um conceito humanitário que assume a qualidade de direito. E como dito, a concretude do cosmopolitismo, nos moldes do projeto de Kant, demanda um avanço ainda maior da humanidade, um processo que está condicionado ao progresso moral do homem para que, assim, o Direito Cosmopolita, um dos requisitos embasadores da Paz Perpétua, seja, de fato, observado.

Assim, por meio da presente pesquisa foi possível concluir que há estreita relação entre o Direito Cosmopolita e a figura do refugiado. Permitindo-se sedimentar a ideia de que não importa em que lugar do mundo o homem esteja, a sua condição humana não o abandona, e é essa a característica que o torna destinatário de proteção, não obstante deva ser reconhecido que nem sempre a característica humana é algo suficiente para tornar o indivíduo digno de consideração pelo outro, pois, com base no pensamento de Hannah Arendt (2012), a impressão é a de que o homem que não é nada além de um homem acaba perdendo todas as qualidades capazes de fazer com que os outros o tratem como semelhante.

O mundo vive uma severa crise humanitária, despontando como única alternativa o urgente reconhecimento da interdependência humana como espécie, exigindo-se o afastamento de quaisquer tentativas de separação e antagonismo entre os povos. É preciso que o ideal cosmopolita seja almejado e gradativamente conquistado, e que a humanidade encontre novas formas de convivência em sociedade, prezando pela hospitalidade, pela solidariedade e pelo respeito mútuo. E que a mensagem que permeia o fictício tratado de paz kantiano, a mensagem da hospitalidade e da igualdade entre os homens, seja capaz de viabilizar o resgate das pessoas que, em razão da perda de sua comunidade, sofrem com a carência de um pertencimento mundial.

\section{REFERÊNCIAS BIBLIOGRÁFICAS}

ALMEIDA, Guilherme Assis de. A Proteção da Pessoa Humana no Direito Internacional: conflitos armados, refugiados e discriminação racial. São Paulo: CLA Cultural, 2018.

ALMEIDA, Guilherme Assis de. Direitos Humanos e Não Violência. 2. ed. São Paulo: Atlas, 2015. 
ARENDT, Hannah. Origens do totalitarismo. Tradução Roberto Raposo. São Paulo: Companhia das Letras, 2012.

BAUMAN, Zygmunt. Danos Colaterais: desigualdades sociais numa era global. Tradução: Carlos Alberto Medeiros. Rio de Janeiro: Zahar, 2013.

BAUMAN, Zygmunt. Estranhos à nossa Porta. Tradução: Carlos Alberto Medeiros. Rio de Janeiro: Zahar, 2017.

BOBBIO, Norberto. A Era dos Direitos. Tradução Carlos Nelson Coutinho. Rio de Janeiro: Elsevier, 2004.

DOUZINAS, Costas. O Fim dos Direitos Humanos. Tradução Luzia Araújo. São Leopoldo: Unisinos, 2009.

GILBERTO, Camila Marques. A Proteção aos Refugiados no Sistema Interamericano de Direito Humanos: reflexões a partir do caso Pacheco Tineo. Dissertação (Mestrado em Direito Internacional) - Universidade Católica de Santos. Santos, 2016.

GODOY, Gabriel Gualano de. Refúgio, Hospitalidade e os Sujeitos do Encontro. In: GEDIEL, José Antônio Peres; GODOY, Gabriel Gualano de. (Orgs.) Refúgio e Hospitalidade. Curitiba: Kairós Edições, 2016.

KANT, Immanuel. À Paz Perpétua. Tradução Artur Morão. Universidade da Beira Interior Covilhã, 2008.

ONU. Convenção de 1951 sobre o Estatuto dos Refugiados. Disponível em:

https://www.acnur.org/fileadmin/Documentos/portugues/BDL/Convencao_relativa_ao_Estatu to_dos_Refugiados.pdf. Acesso em: 20 mar. 2019

PITA, Agni Castro. Direitos Humanos e Direito Internacional dos Refugiados. In: GEDIEL, José Antônio Peres; GODOY, Gabriel Gualano de. (Orgs.) Refúgio e Hospitalidade. Curitiba: Kairós Edições, 2016.

RABENHORST, Eduardo R. Direitos Humanos e Globalização Contra-hegemônica: notas para o Debate. In: LYRA, Rubens Pinto. Direitos Humanos: os Desafios do Século XXI uma abordagem interdisciplinar. Brasília: Brasília Jurídica, 2002.

RAMOS, André de Carvalho. Curso de Direitos Humanos. $4^{\text {a }}$ ed. São Paulo: Saraiva, 2017.

TRINDADE, Antônio Augusto Cançado. Desafios e Conquistas do Direito Internacional dos Direitos Humanos no Início do Século XXI. In: XXXIII Curso de Direito Internacional Organizado pela Comissão Jurídica Interamericana da OEA. Rio de Janeiro, 2006. Disponível em: https://www.oas.org/dil/esp/407-

490\%20cancado\%20trindade\%20OEA\%20CJI\%20\%20.def.pdf Acesso em: 29 mar. 2019.

ZANELLA, Diego Carlos. O Cosmopolitismo Kantiano: do Melhoramento dos Costumes Humanos à Instituição da Paz. Tese (Doutorado em Filosofia) - Faculdade de Filosofia e Ciências Humanas, Pontifícia Universidade Católica do Rio Grande do Sul. Rio Grande do Sul, 2012. 